\title{
Efetividade das políticas participativas no governo brasileiro: o Conselho de Desenvolvimento Econômico e Social
}

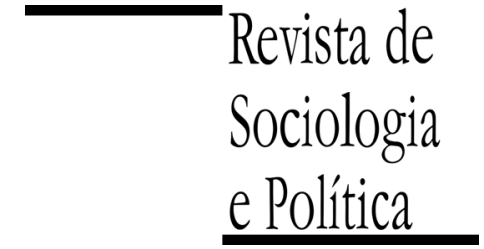

DOI 10.1590/1678-987315235601

\author{
Priscilla Ribeiro dos Santos \\ e Alfredo Alejandro Gugliano
}

Resumo

Na última década, o governo brasileiro diversificou os fóruns de interlocução com a sociedade civil na gestão das políticas públicas. Com base nessa proposta, o Conselho de Desenvolvimento Econômico e Social (CDES) foi criado em 2003 para assessorar a Presidência da República quanto às políticas desenvolvimentistas. Este artigo tem como objetivo analisar a efetividade do CDES no que tange a interlocução com a sociedade civil e a incidência no processo decisório das políticas governamentais no período de 2003 a 2012. Buscamos compreender em que medida o desenho institucional (fator endógeno) e a articulação interna de governo (fator exógeno ou contextual) impactaram sua efetividade. Para tanto, foi empreendida uma pesquisa de natureza qualitativa com base na análise documental, na qual utilizamos o decreto de criação, o termo de referência, as atas e os demais documentos estratégicos produzidos pelo Conselho. Verificou-se que há constrangimentos para a sua efetividade no que tange a democratização dos processos internos, tais como: (i) ausência de critérios transparentes para escolha de seus integrantes e (ii) baixa capacidade inclusiva do quadro de conselheiros não governamentais. Também quanto à coordenação governamental, a proximidade com a coordenação política de governo e a ausência de articulação com os demais fóruns participativos nacionais comprometeram a capacidade propositiva e o encaminhamento das deliberações do CDES. Tendo em vista que as administrações municipais e estaduais têm criado conselhos de desenvolvimento análogos, este estudo pretende contribuir ao debate sobre a influência do desenho institucional e da coordenação governamental na qualificação das políticas participativas.

PALAVRAS-CHAVE: participação, sociedade civil, Conselho de Desenvolvimento Econômico e Social, políticas públicas, efetividade.

Recebido em 16 de Abril de 2014. Aceito em 16 de Julho de 2014.

\section{Introdução ${ }^{1}$}

\footnotetext{
${ }^{1}$ Este artigo é uma versão revisada da dissertação de mestrado, defendida no Pograma de Pós-Graduação de Ciência Política da Universidade Federal do Rio Grande do Sul (UFRGS), de autoria de Priscilla Ribeiro dos Santos e orientação de Alfredo Alejandro Gugliano. Agradecemos as sugestões dos pareceristas anônimos da Revista de Sociologia e Política, bem como as contribuições de Claudia Feres Faria, Lígia Mori Madeira e Soraya Côrtes.

2 Por instituições participativas entendemos formas de inclusão dos cidadãos e organizações da sociedade civil nos processos
}

$\mathrm{N}$ as últimas décadas, as experiências participativas adquiriram visibilidade internacional ao se constituírem como instrumentos de aprofundamento democrático e de qualificação da gestão pública. Experiências como o orçamento participativo foram caracterizadas como inovações democráticas (Avritzer \& Navarro 2003; Wampler 2003), que teriam o potencial de fortalecer a democracia por meio da coexistência e complementaridade entre a participação e a representação.

Entende-se que as instituições participativas atuam em complementaridade às instituições da democracia representativa, visando preencher a lacuna existente entre as demandas da sociedade civil e as decisões estatais, que se baseavam na aferição de interesses via formação de maiorias eleitorais ${ }^{2}$. Por meio de processos participativos, abre-se a possibilidade de uma maior inclusão da sociedade nos processos decisórios, a partir do pressuposto de que os atores sociais possuem capacidade de propor soluções para demandas e problemas locais, influenciando positivamente na gestão do público. Nesta perspectiva, o voto não é o único elemento legitimador das ações de governo, passando a emergir a possibilidade de interlocução com os atores da sociedade civil. 
de deliberação sobre as políticas públicas (Avritzer 2008, p. 45).
Diferentemente dos modelos de gestão pública que preconizam a tomada de decisão por parte de uma equipe técnica de gestores, a participação prevê um processo de compartilhamento de informações e discussões coletivas. Se, no primeiro modelo, as informações detidas pela burocracia não necessitariam ser públicas ou partilhadas com os atores sociais, nos processos participativos a tomada de decisões se dá frente à necessidade desses atores construírem coletivamente uma solução aos problemas da comunidade.

São diversas as experiências de participação social incorporadas à administração pública brasileira nos últimos anos. Desde a Constituição de 1988, uma nova institucionalidade participativa tem se formado, principalmente em âmbito local, por meio da criação de conselhos gestores de políticas públicas, orçamentos participativos (OPs), consultas populares e planos diretores municipais.

Em função do histórico de proximidade do Partido dos Trabalhadores (PT) com movimentos sociais e organizações da sociedade civil, eram grandes as expectativas quanto ao fortalecimento de práticas participativas no governo federal a partir da eleição de Lula em 2003. Até 2010, o governo criou novos conselhos, revitalizou aqueles já existentes e realizou 74 conferências nacionais em diversas áreas (SG/PR 2013).

Em virtude da diversidade de experiências, multiplicaram-se os estudos sobre participação no Brasil nas últimas décadas. Tendo em vista a consolidação dos processos participativos, atualmente, os estudos têm problematizado a qualidade e os efeitos produzidos em termos de aprofundamento democrático e qualificação da gestão pública. A literatura nacional na área tem buscado avaliar a efetividade da deliberação em experiências participativas (Fuks 2007; Cunha 2010; Almeida \& Cunha 2011), a capacidade de as instituições participativas influenciarem, controlarem ou decidirem o conteúdo das políticas públicas (Côrtes 2002; Avritzer 2011; Vaz \& Pires 2011; Vaz 2011), a relação entre participação e representação (Gurza Lavalle, Houtzager \& Castello 2006; Avritzer 2007; Lüchmann 2007) e o potencial das práticas participativas e deliberativas no fortalecimento das instituições representativas como o Congresso nacional (Pogrebinschi \& Santos 2011).

Num contexto de institucionalização da participação na administração pública federal e de formulação de políticas promotoras de desenvolvimento, é criado o Conselho de Desenvolvimento Econômico e Social (CDES). Também chamado de "conselhão", seu formato se diferencia de conselhos de políticas que atuam em áreas estruturadas em sistemas nacionais e com atribuições legalmente estabelecidas. Com elevado número de representantes da sociedade civil, o CDES é um órgão de assessoramento da Presidência da República com o objetivo de apreciar e produzir indicações normativas, propostas políticas e acordos de procedimento sobre a temática do desenvolvimento nacional (Brasil 2003).

A produção acadêmica sobre o CDES é reduzida. De modo geral, os estudos descrevem a dinâmica de funcionamento nos anos iniciais (Kunrath 2005; Kowarick 2006; Ribeiro 2009) e problematizam o potencial da concertação ou pactuação social para o desenvolvimento (Fleury 2003; Costa 2006; Pinto \& Cardoso Jr. 2010). Em termos de teses e dissertações, sobretudo em Ciência Política, o trabalho de Kunrath (2012) propõe uma análise comparada dos conselhos brasileiro e espanhol. Também, em virtude da criação de conselhos similares em outros níveis de governo, estão sendo desenvolvidas pesquisas sobre o impacto desse tipo de experiência participativa nas administrações públicas estaduais (Danéris 2012). 
3 A Rede tem por objetivos: (i) criar um ambiente de diálogo e de troca de saberes entre os participantes, a fim de estabelecer uma agenda comum de debates e (ii) estimular e dar suporte para a criação de novos conselhos municipais ou estaduais (CDES 2014).
Os conselhos estaduais e municipais possuem sua estrutura vinculada ao Gabinete do Executivo e seu funcionamento é similar ao CDES nacional, com atividades permanentes de acompanhamento de projetos estratégicos e subdivisões em grupos de trabalho sobre temáticas do desenvolvimento. Até 2014, estavam em funcionamento os Conselhos de Desenvolvimento Econômico e Social de Pernambuco, Bahia, Rio Grande do Sul, Distrito Federal, Espírito Santo, Paraná, Alagoas, Paraíba e Maranhão. Nos municípios, há a atuação de conselhos similares em Goiânia (GO), Canoas (RS), Erechim (RS), Passo Fundo (RS), Diadema (SP), São Pedro (SP), São Carlos (SP), Presidente Venceslau (SP) e Santarém (PA). Tais conselhos integram a Rede Brasileira de Conselhos de Desenvolvimento Econômico e Social, criada em $2012^{3}$.

Este artigo pretende contribuir para a compreensão dos Conselhos de Desenvolvimento Econômico e Social como um novo formato de instituição participativa, que visa democratizar a gestão pública por meio do diálogo com representantes da sociedade civil sobre a temática do desenvolvimento. Buscamos avaliar as regras e os procedimentos que orientam o funcionamento e as práticas dos atores sociais e estatais que compõem o CDES da Presidência da República, atentando também para seu potencial inclusivo e democratizante. Nesse sentido, a análise sobre a efetividade de seus trabalhos busca verificar as potencialidades e as limitações desse modelo para a inclusão da sociedade civil no debate sobre os programas governamentais, diante da necessidade de aprimorar o sistema político e fortalecer as instituições democráticas no Brasil.

Tendo em vista que as administrações municipais e estaduais têm criado conselhos de desenvolvimento análogos, este estudo pretende contribuir ao debate sobre a influência do desenho institucional e da articulação interna de governo na qualificação das políticas participativas. Na perspectiva discutida por Faria (2007), por "efetividade" entende-se a capacidade das instituições participativas incluírem novas e diferentes vozes nos processos de formulação, implementação e monitoramento das políticas, ampliando o escopo da deliberação e expandindo o acesso aos bens públicos.

Composto por duas principais seções, primeiramente o artigo apresenta um mapeamento das políticas participativas no governo Lula, em especial a criação de novos conselhos. A segunda seção avalia a efetividade do CDES a partir de variáveis como organização e funcionamento, processo decisório, presidência, composição, agendamento e articulação interna de governo. Com base na análise documental, verificamos que há constrangimentos para a efetividade do Conselho no que tange o potencial inclusivo e de democratização dos processos internos, tais como: ausência de critérios transparentes para escolha dos representantes da sociedade civil, sobrerrepresentação de determinados segmentos e não rotatividade da presidência. A proximidade com a coordenação política de governo, aliada à ausência de articulação com os demais fóruns participativos nacionais, comprometeram a capacidade propositiva dos conselheiros da sociedade civil, facilitando a sobreposição da agenda governamental no período estudado.

\section{Políticas participativas no governo Lula}

A gestão participativa está sendo institucionalizada no âmbito da administração pública brasileira nas duas últimas décadas. Governos municipais, estaduais e federal viabilizaram a criação de novos canais de interlocução com a sociedade civil para a gestão das políticas públicas, contribuindo para a transformação das relações entre o Estado e a sociedade. Nesse sentido, os processos participativos têm produzido novas redes e novas interações entre grupos sociais e atores estatais, revelando diferentes graus de institucionalização de 
${ }^{4}$ O percentual de ministérios e de órgãos da administração que continham mecanismos de interlocução com a sociedade civil sofreu incremento positivo, passando de $60,4 \%$, em 2002, para 89,3\% em 2010. O número de programas federais com interfaces socioestatais já era elevado em 2002 , com percentual igual a $81 \%$, mas ainda houve uma variação positiva até o ano 2010, totalizando $92,1 \%$ (IPEA 2012).

\footnotetext{
${ }^{5}$ Sobre a caracterização dos conselhos nacionais,
}

acordo com o nível de governo e a dinâmica política no interior de cada setor de política pública (Wampler 2010; Abers, Serafim \& Tatagiba 2014).

No âmbito do governo federal, a partir de 2003, novas instituições participativas passaram a integrar os sistemas de políticas públicas em áreas como cidades, segurança alimentar e nutricional, economia solidária, promoção da igualdade racial e juventude. Em virtude das inovações democráticas implementadas pelo Partido dos Trabalhadores nas gestões municipais, a exemplo do orçamento participativo, eram grandes as expectativas quanto ao governo Lula em termos da participação popular e cidadã. Dentre as principais ações executadas, destacam-se: o fortalecimento e a criação de conselhos e conferências, a participação no debate sobre os Planos Plurianuais e a criação da Secretaria Nacional de Articulação Social na estrutura da Secretaria-Geral da Presidência (Faria 2010).

Em estudo realizado pelo IPEA (2012), foi verificada a diversificação e o aumento do número de órgãos da administração pública federal com interfaces socioestatais no período de 2002 a 2010. Também um maior número de programas desenvolvidos pelo governo federal passou a contemplar mecanismos de interlocução com a sociedade civil, a exemplo de ouvidorias, reuniões com grupos de interesse, audiências e consultas públicas, discussão em conselhos setoriais e em conferências temáticas ${ }^{4}$. Esses canais de interlocução diferem quanto ao nível de participação social que objetivam promover dentro da estrutura institucional (IPEA 2012): enquanto alguns visam promover a participação da sociedade civil na elaboração de políticas setoriais, como no caso dos conselhos, das conferências e das consultas públicas, outros se configuram como espaços de transparência e de controle social, nos quais a população é convidada a incidir na fiscalização, no monitoramento e no controle das ações públicas, como no caso das ouvidorias.

Dentre os mecanismos de participação social, os conselhos nacionais se destacam por seu caráter inclusivo e inserção nos sistemas de políticas setoriais. Os conselhos são instituições presentes na política brasileira há décadas, estando vinculados ao Poder Executivo para a deliberação e/ou consulta sobre assuntos diversos. A partir da redemocratização, um maior número de conselhos passou a reunir um expressivo conjunto de representantes da sociedade civil em diálogo com os gestores públicos, num formato de "instituição híbrida" (Avritzer \& Pereira 2005).

Para além da discussão acerca do viés participativo no processo de elaboração de políticas públicas, a criação de conselhos sinaliza uma redução dos custos políticos para o encaminhamento dos projetos do Executivo. Ao criar conselhos consultivos ou deliberativos, o Executivo potencializa sua capacidade de intermediário na relação entre interesses sociais diversos, possibilitando uma forma cooperativa e pública de negociação social para se chegar a acordos políticos. Podendo o conselho cumprir o papel de um termômetro social, de aceitação ou repulsa das políticas governamentais, ele constitui uma etapa de consulta e diálogo entre o poder público e a sociedade civil, caracterizando um processo de negociação, no qual ganhos e perdas são compartilhados entre os participantes. Uma vez aprovados por uma parcela social representativa, os projetos e as ações políticas que propõem reformas estruturais de enfrentamento às condições de desigualdade e promoção do desenvolvimento adquirem maior legitimidade, podendo acelerar o caminho percorrido entre o debate político e o planejamento das políticas.

No período que compreende os dois mandatos do presidente Lula, há um aumento significativo no número de conselhos e comissões nacionais com participação da sociedade civil. No caso dos conselhos nacionais ${ }^{5}$, de 31 conselhos em funcionamento em 2010, 13 eram consultivos (42\%) e 18 eram 
utilizamos os seguintes critérios definidos pelo IPEA (2010): centralidade para a gestão das políticas públicas, criação por ato normativo e expressiva participação de representantes da sociedade civil. Assim, estariam excluídos os conselhos curadores, os conselhos gestores de fundos e aqueles com reduzida participação da sociedade civil. deliberativos (58\%). Os dois formatos distinguem-se quanto ao poder de decisão sobre as temáticas nas quais estão referenciados. Enquanto os conselhos deliberativos possuem capacidade de produzir decisões vinculantes sobre políticas e programas, conselhos consultivos caracterizam-se como espaços de discussão, mas sem o poder de constituir decisões finais.

Segundo dados do IPEA (2010), no período de 1989 a 2002, houve maior tendência de criação de conselhos deliberativos do que consultivos. Em grande medida, a criação desses conselhos visou atender o conteúdo constitucional e a legislação ordinária derivada da regulamentação dos sistemas nacionais de políticas públicas em áreas como educação e assistência social. No entanto, no período Lula (2003-2010), foram criados mais conselhos consultivos (nove) do que deliberativos (seis). Esse dado revela que a inclusão da sociedade civil em conselhos nacionais, notadamente a partir de 2003, privilegiou a formatação de decisões não vinculantes ao conteúdo das políticas.

Dentre os conselhos nacionais com caráter consultivo, destacamos a criação do Conselho de Desenvolvimento Econômico e Social em 2003. Diferentemente da caracterização proposta por Avritzer (2010b), o modelo no qual o CDES está referenciado não pressupõe a articulação federativa, não discute políticas setoriais, nem controla instrumentos de financiamento. Sua criação é posterior aos movimentos sociais pós-Constituinte e tem no Presidente da República seu principal idealizador.

\section{Conselho de Desenvolvimento Econômico e Social: condicionantes da efetividade}

O entusiasmo inicial, que inspirou inúmeros estudos na década de 1990 e início dos anos 2000, tem cedido lugar para análises criteriosas, que buscam avaliar a efetividade e o potencial democratizante das experiências participativas. Dentre as principais contribuições para sistematizar o debate teórico e estabelecer um nível de comparabilidade entre as experiências, destacam-se as iniciativas de Avritzer (2010a) e de Pires (2011), que reúnem coletâneas de artigos sobre a avaliação das instituições participativas no Brasil.

Segundo Avritzer (2011), grande parte dos estudos recentes sobre a efetividade participativa tem origem na literatura norte-americana sobre democracia deliberativa. Em linhas gerais, a referida literatura compreende que a deliberação pública exprime um acordo geral, dialógico e cooperativo, que melhora a qualidade da justificação política e da produção de decisões. Ao conceber a deliberação não como um processo agregativo de preferências individuais e fixas, mas como um processo dialógico, que antecede e que auxilia na apropriação de temas (Fung \& Wright 2003; Bohman 2009; Cohen 2009), os teóricos da deliberação pública trazem à tona o problema da troca de razões, enquanto elemento central da formação da vontade política (Avritzer 2011).

Os desafios para tornar o modelo deliberativo viável partem da necessidade de operacionalização dos procedimentos de deliberação em sociedades complexas e, sobretudo, de condições igualitárias para o processo comunicativo. Segundo Faria (2000), Cohen (2009) e Bohman (2009) buscam analisar como as instituições podem se tornar mais democráticas por meio da qualificação dos métodos e condições de debate. Para tanto, sugerem uma operacionalização mais factível da deliberação pública pela criação de arranjos institucionais que promovam a soberania popular.

Segundo Bohman (2009), a deliberação pública é eminentemente dialógica e almeja superar uma situação problemática por meio de uma atividade conjunta e cooperativa entre os atores, aperfeiçoando a qualidade das razões empregadas na justificação política. Nessa perspectiva, a prática deliberativa gera uma base recursiva e reflexiva, que implica positivamente práticas de accountability e de 
controle público. Com base nas leituras de Faria (2000) e Lüchmann (2002), a Poliarquia Diretamente Deliberativa de Cohen parte da crítica ao modelo habermasiano que limita o potencial da deliberação na esfera pública à influência no mundo sistêmico. Cohen concebe que, para resolver problemas que afetam o cotidiano dos indivíduos, é preciso estimular a criação de espaços institucionalizados de participação no nível local com reais condições de implementação das decisões no âmbito sistêmico, de modo a garantir a soberania popular (Faria 2000; Lüchmann 2002).

Cabe destacar que os teóricos da deliberação pública trouxeram subsídios sobre os condicionantes da efetividade das instituições participativas ao colocarem a questão da busca do desenho institucional adequado para a deliberação (Avritzer 2011, p. 15). Nos últimos anos, a abordagem deliberacionista subsidiou diversos estudos no Brasil, abrangendo experiências diversas, como orçamentos participativos, audiências públicas, conselhos nas áreas de saúde, assistência social, entre outros (Faria 2005; Fuks 2007; Cunha 2010; Almeida \& Cunha 2011; Horochovski \& Clemente 2012).

Uma série de fatores pode incidir sobre a efetividade da participação, compreendendo desde a dinâmica associativa até a capacidade técnico-administrativa para dar encaminhamento às deliberações pactuadas. Dentre os principais determinantes que afetam o desempenho das instituições participativas, a literatura destaca: desenho institucional, tradição associativa, orientação ideológica do governo, capacidades financeira e administrativa, organização dos movimentos popular e sindical e desenvolvimento socioeconômico local (Côrtes 2002; Silva 2003; Avritzer 2008; Cunha et al., 2011).

Em análise sobre três experiências participativas distintas (orçamentos participativos, conselhos de políticas e planos diretores municipais), Avritzer (2008) avalia em que medida o contexto atua como variável relevante para a efetividade da participação para além da centralidade atribuída aos desenhos institucionais (Fung \& Wright 2003; Fung 2004). Nessa perspectiva, o êxito das instituições participativas é justificado pela articulação entre desenho institucional, organização da sociedade civil e vontade política do governo em implementar a participação (Avritzer 2008, p. 46). O referido estudo conclui que os orçamentos participativos têm o maior potencial democratizante e distributivo em virtude da combinação de associativismo local, vontade política dos governantes e formas institucionais de participação constituídas de baixo para cima. Assim como no caso dos orçamentos participativos, a efetividade dos conselhos de políticas também depende de forte organização da sociedade civil. Porém, seu desenho de partilha de poder faz com que o nível de dependência do sistema político seja intermediário, tendo em vista que sanções podem ser aplicadas no caso de não implementação, como nos conselhos de saúde. Em linhas gerais, o autor argumenta que práticas associativas e fatores contextuais não só afetam o desempenho da participação, mas também a escolha do desenho institucional.

Neste artigo, argumentamos que o desempenho das instituições participativas é impactado tanto por fatores endógenos (Faria \& Ribeiro 2010), quanto por fatores exógenos ou contextuais (Avritzer 2008). Para efeitos de análise, adotou-se a formulação de Cunha et al. (2011), que propõem uma estratégia multidimensional para a investigação das experiências participativas. A partir da constatação de que há uma lacuna metodológica nos estudos que propõem uma avaliação dos efeitos produzidos por instituições participativas, os autores retomam as reflexões de Castiglione \& Warren (2006) quanto à necessidade do aperfeiçoamento de técnicas para análise da qualidade do processo de tomada de decisão e de verificação do impacto da participação de atores da sociedade civil no sistema político. 
${ }^{6}$ Na perspectiva discutida pelas autoras, as escolhas e as variações entre os desenhos institucionais não são aleatórias, impactando diretamente o funcionamento e os resultados produzidos pela participação (Faria \& Ribeiro 2010, p.62).
Buscamos compreender em que medida o desenho institucional (fator endógeno) e a articulação interna de governo (fator exógeno ou contextual) impactaram a efetividade do CDES no período de 2003 a 2012. Argumentamos que o desenho institucional, compreendido como um conjunto de regras, mecanismos e processos que definem os parâmetros para a implementação e o funcionamento de determinada política pública é um fator relevante para a efetividade das instituições participativas. A análise sobre o impacto das variáveis institucionais no desempenho dos conselhos de políticas públicas teve por referência o estudo de Faria \& Ribeiro (2010) ${ }^{6}$, tendo sido utilizadas as seguintes variáveis: (i) organização e funcionamento; (ii) processo decisório; (iii) regras para a definição da presidência e (iv) composição. Quanto à articulação interna de governo, foram analisados dados referentes à $(v)$ coordenação dos processos participativos nacionais e (vi) à vinculação institucional do CDES. Foi empreendida uma pesquisa de natureza qualitativa com base na análise documental, na qual utilizamos o decreto de criação, o termo de referência, as atas e os demais documentos estratégicos produzidos pelo CDES no período referido.

\section{III.1 Desenho institucional: organização, funcionamento e processo decisório}

${ }^{7}$ Nota-se que, na própria nomenclatura do conselho, ele se distingue dos modelos europeus. O CDES nacional inclui no seu nome o interesse em debater o

desenvolvimento, com o objetivo de iniciar um novo ciclo de planejamento quanto ao tema, priorizando os enfoques econômico e social.
Criado por Medida Provisória, em $1^{\circ}$ de janeiro de 2003, e regulamentado pela Lei $n^{\circ} 10.683$, de 28 de maio de 2003, o CDES brasileiro foi inspirado nos modelos de Conselhos Econômicos e Sociais de Portugal e Espanha, criados após 1970. Tais experiências visaram debater o conflito distributivo, sob moldes democráticos, ampliando as discussões a respeito do conteúdo das reformas estatais de médio e longo prazo em uma perspectiva neocorporativa. Isto é, um modelo que estimula a representação de interesses associativos da sociedade civil com o Estado (Schmitter 1979).

A criação de Conselhos Econômicos e Sociais pode ser compreendida a partir de três momentos distintos (Fleury 2003). O primeiro corresponderia ao período posterior à II Guerra Mundial e de constituição do Welfare State; contexto no qual foram criados os conselhos da França, Itália, Bélgica e Holanda. $\mathrm{O}$ segundo momento remete à terceira onda democrática e à transição dos regimes autoritários no sul da Europa, no qual se contextualiza a criação dos conselhos de Portugal e Espanha. O terceiro momento inicia no final dos anos 1990, com os primeiros sinais da crise econômica mundial e esgotamento dos paradigmas neoliberais. Tal momento perdura até os dias de hoje com uma matriz que busca o diálogo entre sociedade civil e Estado para a formulação de propostas de desenvolvimento socioeconômico e redução das desigualdades. É nesta última fase que é possível incluir a criação do Conselho de Desenvolvimento Econômico e Social brasileiro ${ }^{7}$ (Fleury 2003; Danéris 2012).

Os Conselhos Econômicos e Sociais se identificam pelo caráter consultivo aos poderes constituídos, tendo a tarefa de emitir pareceres diante de decisões que remetam às questões que necessitam de uma pactuação entre diferentes atores sociais. Sem poder deliberativo e de alocação de recursos, tais conselhos possibilitam o trânsito das políticas governamentais antes do encaminhamento ao Congresso Nacional, diminuindo os custos de transação ou o desgaste político na relação com o Legislativo. Embora Avilés (1992) afirme que, historicamente, tais conselhos não desempenharam protagonismo nos processos de tomada de decisões, é preciso avançar na análise quanto aos fatores que influenciam a efetividade dos conselhos como novas oportunidades de acesso institucional para organizações da sociedade civil.

Assim como os conselhos europeus, o CDES brasileiro trabalha com a metodologia da concertação social - experiência até então inovadora, que demanda uma análise atenta sobre seus participantes e o fluxo comunicacional entre eles. Diferentemente dos demais conselhos nacionais, as deliberações do 
${ }^{8}$ Desde 2006, o Observatório da Equidade funciona como uma estrutura anexa ao CDES com a finalidade de produzir trabalhos técnicos. É composto por 12 conselheiros e uma equipe interinstitucional com especialistas do IPEA, do IBGE e do DIEESE.
CDES excluem votações, trabalhando pela busca do consenso entre seus participantes. A metodologia da concertação prevê que as pautas do Conselho avancem somente quando as temáticas não envolvem conflitos insolúveis de interesses entre grupos sociais. As proposições acordadas no pleno do CDES são fruto de um esforço dialógico e argumentativo de seus participantes, sem a formação de maiorias ou minorias. No entanto, ainda é facultado aos conselheiros o encaminhamento à Presidência de recomendações não consensuais (Brasil 2003).

Um conjunto de instâncias compõe sua estrutura, sendo responsáveis pelo trânsito de conteúdos entre a equipe governamental e os conselheiros. A Secretaria Executiva do Conselho (SEDES) é responsável pela coordenação dos trabalhos, convocação dos conselheiros e promoção do diálogo com a equipe governamental. A SEDES atua como mediadora do diálogo entre o núcleo de governo e os conselheiros da sociedade civil, fornecendo os subsídios administrativos necessários para o bom funcionamento do conselho, que vão desde a existência de um espaço físico adequado até a relatoria das reuniões. Todo tema, seja ele proposto pelos conselheiros, seja pela Presidência da República, passa necessariamente pela gestão da Secretaria. No caso de ausência do Presidente, o secretário-executivo da SEDES é responsável pela condução das reuniões plenárias. As dinâmicas de funcionamento e de encaminhamento das pautas podem ser visualizadas na Figura 1 (na próxima página).

As regras para o funcionamento de suas instâncias internas, bem como os critérios de composição e periodicidade estão previstos em decreto (Brasil 2003). As instâncias internas do Conselho são o pleno, os grupos temáticos (GTs) ou grupos de acompanhamento e o comitê gestor ${ }^{8}$. O pleno do conselho reúne todos os conselheiros, representantes da sociedade civil e do governo, e se caracteriza como uma reunião de trabalho com periodicidade bimestral. O pleno é responsável pela apreciação inicial e final das temáticas encaminhadas pelos conselheiros ou pela Presidência. Somente o pleno autoriza a criação dos grupos temáticos ou de acompanhamento, validando o conteúdo proposto por estes (conforme Figura 1). Ao todo, 39 reuniões plenárias foram realizadas no período de 2003 a 2012.

A presença de comissões internas ou grupos temáticos permite a apropriação da temática, diminuindo as assimetrias de informação e capacitando os participantes a tomarem decisões (Faria 2007). No caso do CDES, os GTs são criados pelo pleno e tem como objetivo reunir conselheiros interessados em debater determinada matéria de forma aprofundada. Segundo decreto (Brasil 2003), até nove grupos podem estar em funcionamento simultaneamente. São compostos por dois representantes do governo (um funcionário da SEDES e um representante do Ministério relativo à temática), dez conselheiros do CDES e até nove cidadãos convidados pelo Secretário-Executivo do Conselho. Não há critérios para a periodicidade de suas reuniões. Até 2012, 20 grupos de trabalho foram criados, tendo encaminhado variados acordos e recomendações para aprovação do pleno.

Uma instância fundamental para a organização das atividades do Conselho é o comitê gestor. Criado em 2008, o comitê tem por objetivos organizar a agenda do Conselho, atuar na interlocução com a equipe de governo e acompanhar os encaminhamentos das deliberações do pleno. É composto por seis conselheiros representantes da sociedade civil e dois representantes do governo (integrantes da SEDES) para mandatos de seis meses ou duas reuniões plenárias. A escolha dos representantes da sociedade civil é feita pela SEDES, buscando contemplar conselheiros com atuação mais destacada nas atividades, respeitando critério de representatividade social (CDES 2008). 
Figura 1 - Dinâmica de funcionamento do CDES

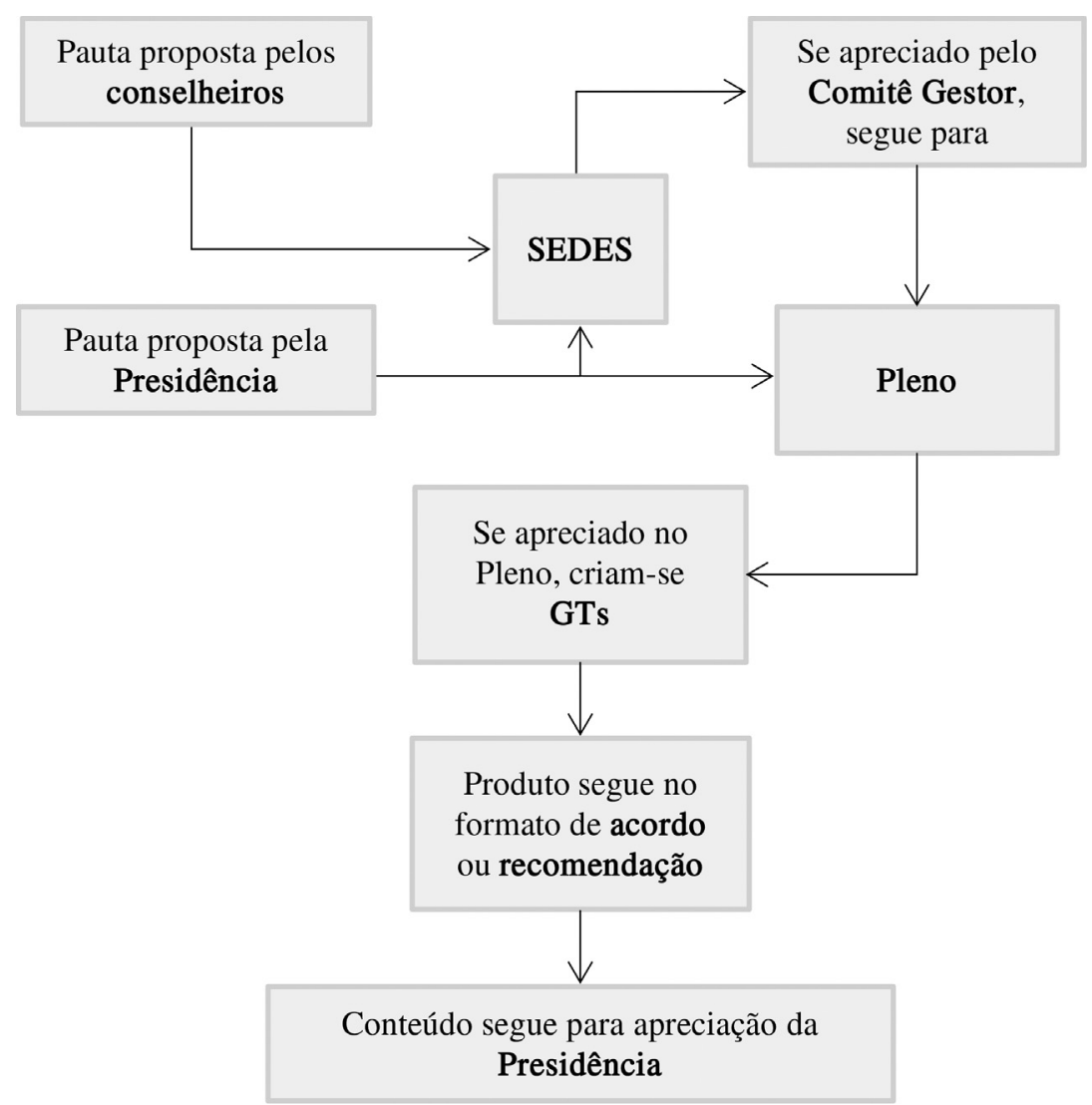

Fonte: Os autores, a partir de Brasil (2003) e CDES (2009).

Este conjunto de procedimentos e instâncias de funcionamento revela o nível de organização e de institucionalização do CDES. No entanto, é necessário atentar para a presença ou ausência de critérios para a alternância da presidência. A possibilidade de alternância do presidente do conselho é um importante indicador de democratização interna (Faria \& Ribeiro 2010). No caso do CDES, não há possibilidade de alternância do presidente, uma vez que somente o chefe do Executivo federal ocupa tal função. Assim, não está previsto um mecanismo de votação do presidente, sendo impossibilitada a candidatura de representantes da sociedade civil. A estes é possibilitada somente a participação no comitê gestor. Em virtude da dinâmica de funcionamento e do processo decisório interno, o presidente é destinatário dos acordos e recomendações produzidos pelos conselheiros. Além disso, o decreto que regulamenta o funcionamento do Conselho não define maiores atribuições ao presidente, restando certa lacuna no que tange suas prerrogativas, principalmente no que tange o poder de vetar determinados assuntos de pauta.

Tendo descrito o funcionamento das principais instâncias do Conselho, a seguir, é analisada a composição do quadro de conselheiros no período de 2003 a 2012.

\section{III.2 Composição e distribuição dos participantes}

De modo geral, os conselhos nacionais são compostos por representantes governamentais e por conselheiros provenientes da sociedade civil, indicados pelos próprios gestores públicos ou escolhidos por organizações ou movimen- 
${ }^{9}$ Utilizou-se como fonte o material disponibilizado na página oficial do Conselho, onde é possível encontrar breves currículos dos participantes de acordo com o ano de mandato (CDES 2012b). tos sociais. Tendo em vista que o CDES possui um caráter de assessoramento exclusivo ao chefe do Poder Executivo, sua composição está subordinada à escolha presidencial. O CDES possui a presença majoritária de conselheiros não governamentais, que são indicados de modo a combinar "reconhecida liderança e representatividade setorial" (Brasil 2003). Os mandatos dos representantes da sociedade civil são de dois anos, podendo ser prorrogável por igual período. Os conselheiros governamentais são ministros de Estado, designados pela Presidência, conforme decreto. As estatísticas descritivas sobre os conselheiros são consultadas na tabela 01 a seguir:

Com base nas informações divulgadas na página virtual do $\mathrm{CDES}^{9}$, foram criadas seis categorias para identificação dos conselheiros participantes: $(i)$ lideranças de movimentos sociais e de organizações não governamentais (ONGs); (ii) professores universitários; (iii) trabalhadores; (iv) empresários; (v) representantes de governo e (vi) outros. Conforme a tabela 01, é majoritária a presença de conselheiros não governamentais no período. Até 2009, ocorre uma pequena variação nos percentuais de representantes governamentais, oscilando de $11,8 \%$ a $13,9 \%$. No entanto, há uma tendência de ampliação deste número a partir de 2010. Em 2011, primeiro ano do governo Dilma Rousseff, 28,5\% do quadro de conselheiros é composto por ministros de Estado.

A partir de 2005, evidencia-se uma tendência à redução do número de conselheiros identificados como lideranças de movimentos sociais e ONGs. Em 2011, apenas 5,7\% do quadro era composto por esse segmento. A mesma tendência é verificada também no caso dos professores universitários. Em contrapartida, o número de conselheiros identificados como trabalhadores tem sofrido variações positivas, sendo que o percentual sobe de 11,8\%, em 2003, para $18,9 \%$ em 2009. No entanto, a categoria mais representada no CDES é a de empresários que, desde 2003, tem percentuais superiores a 38\% do quadro, chegando a 47,6\% em 2012. Nessa categoria foram incluídos representantes de associações, institutos e federações empresariais e financeiras, bem como empresários das áreas de indústria, comércio e serviços.

Diferentemente dos Conselhos Econômicos e Sociais europeus, o Conselho brasileiro não garante em seu regulamento a reserva de mandatos para entidades de classes, associações, organizações e movimentos sociais. A composição do quadro de conselheiros está condicionada unicamente à escolha da Presidência. Apesar dos critérios de reconhecida liderança e representatividade setorial orientarem o processo de escolha dos conselheiros não governamentais (Brasil

Tabela 1 - Conselheiros do CDES no período de 2003 a $2012(\%)$

\begin{tabular}{lcccccccccc}
\hline Conselheiros & $\begin{array}{c}\text { Ano } \\
\mathbf{2 0 0 3}\end{array}$ & $\begin{array}{r}\text { Ano } \\
\mathbf{2 0 0 4}\end{array}$ & $\begin{array}{c}\text { Ano } \\
\mathbf{2 0 0 5}\end{array}$ & $\begin{array}{c}\text { Ano } \\
\mathbf{2 0 0 6}\end{array}$ & $\begin{array}{c}\text { Ano } \\
\mathbf{2 0 0 7}\end{array}$ & $\begin{array}{c}\text { Ano } \\
\mathbf{2 0 0 8}\end{array}$ & $\begin{array}{c}\text { Ano } \\
\mathbf{2 0 0 9}\end{array}$ & $\begin{array}{c}\text { Ano } \\
\mathbf{2 0 1 0}\end{array}$ & $\begin{array}{c}\text { Ano } \\
\mathbf{2 0 1 1}\end{array}$ & $\begin{array}{c}\text { Ano } \\
\mathbf{2 0 1 2}\end{array}$ \\
\hline $\begin{array}{l}\text { Lideranças de movimentos } \\
\text { sociais e ONGs }\end{array}$ & 11,8 & 12,4 & 13,4 & 11,4 & 9,2 & 9,9 & 9,0 & 7,6 & 5,7 & 6,5 \\
Professores universitários & 13,7 & 14,2 & 12,5 & 13,3 & 12,8 & 8,9 & 10,7 & 10,2 & 8,9 & 8,9 \\
Trabalhadores & 11,8 & 12,4 & 12,5 & 14,3 & 17,7 & 18,8 & 18,9 & 18,6 & 16,3 & 16,9 \\
Empresários & 44,1 & 42,5 & 40,2 & 41,0 & 39,7 & 41,6 & 41,8 & 40,7 & 38,2 & 47,6 \\
Representantes do governo & 11,8 & 12,4 & 12,5 & 13,3 & 12,1 & 13,9 & 13,9 & 18,6 & 28,5 & 16,9 \\
Outros & & & & & & & & & & \\
Total (\%) & 6,9 & 6,2 & 8,9 & 6,7 & 8,5 & 6,9 & 5,7 & 4,2 & 2,4 & 3,2 \\
\hline
\end{tabular}

${ }^{1}$ Nesta categoria foram inseridos conselheiros identificados como personalidades das áreas de cultura e esporte.

Fonte: Os autores, a partir de CDES (2012b). 
2003), há evidências de que a indicação obedece mais a um critério pessoal do que de representação de coletividades.

Com base nos dados, é possível afirmar que há limitações quanto à capacidade inclusiva do CDES em virtude da forma de indicação, composição e distribuição dos conselheiros. A ausência de regras sobre garantia de proporcionalidade entre os segmentos e a não possibilidade de indicação de representantes por parte das organizações da sociedade civil revelam problemas de representatividade (Pinto 2004). Há predominância de empresários na composição do CDES, sendo reduzida a participação de lideranças da sociedade civil organizada, por exemplo. Mesmo que o percentual de trabalhadores tenha sofrido um aumento gradual desde 2003, somente os empresários detêm mais de um terço das cadeiras do Conselho.

Tendo em vista que a participação social visa potencializar o diálogo entre os cidadãos e os gestores públicos, possibilitando também a inclusão de atores sociais que historicamente estavam à margem dos processos decisórios, há indícios de que os critérios de seleção e de distribuição dos integrantes do CDES não têm contribuído para sua efetividade enquanto um fórum de vocalização das demandas da sociedade civil brasileira. A análise de sua composição revela a ausência de critérios transparentes para escolha dos participantes, sobrerrepresentação de determinados segmentos e baixo potencial inclusivo.

\section{III.3 Articulação interna de governo: vinculação institucional e coordenação dos processos participativos}

${ }^{10}$ Vale destacar que, em dezembro de 2013, o CDES novamente sofre transferência, passando a integrar a estrutura da Casa Civil da Presidência da República (Brasil 2013).
Como referido, a gestão do CDES é feita pela Secretaria Executiva, denominada SEDES. No período analisado, um total de seis ministros coordenaram as atividades do Conselho. Até 2010, a SEDES esteve sob coordenação governamental da Secretaria de Relações Institucionais (SRI) e, a partir de 2011, passou a estar subordinada à Secretaria de Assuntos Estratégicos (SAE) ${ }^{10}$.

A Secretaria de Relações Institucionais integra a estrutura da Presidência da República e atua na coordenação política, na interlocução com os demais entes federados e na condução do relacionamento do governo com o Congresso e os partidos políticos. Enquanto vinculado à SRI, o CDES acessava um local privilegiado na estrutura governamental, ligado diretamente ao núcleo de assessoramento da Presidência. O trânsito das recomendações do CDES era facilitado graças à proximidade com os gestores responsáveis pela própria coordenação política e pelo diálogo com a esfera legislativa.

Se, ao longo do período Lula, o Conselho esteve fortemente ligado ao núcleo de coordenação política do governo, a partir do Governo Dilma, o CDES passa a ter uma nova inserção institucional, relacionada ao planejamento das políticas para o desenvolvimento. Nesta transição, afirma-se que o Conselho perde peso político e adquire um status mais técnico, estando mais próximo a instituições de pesquisa, como o IPEA. A partir de 2011, o CDES passa a ocupar um local institucional completamente diferente, graças à mudança para a SAE. A Secretaria de Assuntos Estratégicos foi criada em 2008, dentro da estrutura da Presidência da República, para o assessoramento, planejamento e formulação de políticas públicas voltadas ao desenvolvimento nacional. É composta pela Secretaria de Ações Estratégicas, pela Secretaria de Desenvolvimento Sustentável e, desde 2011, pela Secretaria do CDES. Mesmo sem perder seu caráter de aconselhamento, a nova inserção institucional passa a influir na gestão e coordenação da SEDES, assim como no trânsito das recomendações do Conselho ao núcleo de decisão política do governo.

A vinculação institucional do Conselho impacta a formulação de sua agenda. Isto é, quanto mais próximo estiver do núcleo político do governo, maior a tendência de que a agenda do Executivo irá sobrepor-se às temáticas even- 
${ }^{11}$ Quanto ao debate sobre a temática do desenvolvimento no CDES, sugerimos Santos (2014). tualmente sugeridas pelos conselheiros não governamentais. Com base na leitura das atas das reuniões plenárias (CDES 2012a), afirma-se que, enquanto o CDES esteve vinculado à SRI, a agenda governamental pautou os debates promovidos no Conselho, sendo que o pleno serviu de momento estratégico para o informe por parte da equipe ministerial sobre as políticas desenvolvidas pelo governo.

No entanto, o impacto do CDES nos programas governamentais foi limitado, já que os principais documentos produzidos ora tratavam de diretrizes gerais sobre o projeto desenvolvimentista, ora sugeriam alterações incrementais aos textos originais das políticas (CDES 2013). Os principais documentos de orientação produzidos quanto à temática do desenvolvimento foram: a Agenda Nacional de Desenvolvimento, os Enunciados Estratégicos para o Desenvolvimento e a Agenda para um Novo Ciclo de Desenvolvimento ${ }^{11}$.

Até 2010, dentre as proposições incorporadas às ações governamentais, destacam-se: a contribuição ao Plano de Desenvolvimento da Educação, que resultou na criação do FUNDEB, em 2006; a criação do Fórum Nacional do Trabalho, a implementação da Lei Geral das Micro e Pequenas Empresas, em 2007; a incorporação de algumas diretrizes da Agenda Nacional de Desenvolvimento no Programa Nacional de Segurança Cidadã (PRONASCI), lançado em 2008; a elaboração de orientações para os Planos Plurianuais do governo; e a incorporação de critérios sugeridos pelo Conselho ao Programa Minha Casa, Minha Vida (CDES 2013).

A leitura das atas das reuniões plenárias revela que a inclusão de novas pautas sugeridas por atores sociais foi limitada, seja pela ordem de prioridades do governo, seja pelo tempo disponível para o debate. Mesmo tendo a participação majoritária de representantes da sociedade civil, a pauta é definida pelo Executivo, sendo dificultada a inclusão de temáticas externas à agenda governamental. Disso resulta uma perda de autonomia por parte do Conselho, que pode comprometer a qualidade dos debates e até mesmo o resultado das deliberações. Sua atuação se distancia da proposta de uma instância intermediária e de vocalização das demandas das bases dos movimentos e organizações da sociedade civil, pois a capacidade de aconselhamento se restringe à pauta previamente encaminhada pela equipe de governo.

Com a vinculação do CDES à SAE e o afastamento da coordenação política do governo, é perceptível um esvaziamento da pauta, sendo que políticas estratégicas do governo Dilma não tiveram no Conselho um fórum privilegiado de debate. Além disso, houve um distanciamento maior entre as reuniões plenárias, que deixaram de ocorrer a cada dois meses. Nesse sentido, o afastamento do núcleo político acarretou o esvaziamento da pauta e a diminuição da periodicidade das reuniões plenárias. Por outro lado, temos que quanto maior a proximidade do CDES com a coordenação política de governo, maior a sobreposição da agenda governamental e menor a probabilidade de inclusão de pautas sugeridas por conselheiros representantes da sociedade civil.

O formato do CDES também não favorece a articulação com as demais instituições participativas, que atuam na gestão de políticas setorializadas. Tal fato pode comprometer o fortalecimento das agendas da sociedade civil e dificultar os processos de diálogo e negociação. Tendo em vista que o CDES atua no assessoramento sobre macropolíticas para o desenvolvimento, sua integração com os demais processos participativos poderia contribuir para seu fortalecimento, evitando que o Conselho se limite a um fórum de homologação dos programas governamentais.

Quanto à articulação interna de governo, a pesquisa de Teixeira, Souza e Lima (2012) traz evidências que foi construída uma estrutura de gestão no 
12 Dividida em três departamentos (Diálogos Sociais, Participação Social e Educação Popular e Mobilização Cidadã), é de sua competência a proposição e apoio de novos instrumentos de participação, bem como o acompanhamento e a articulação de agendas com entidades e movimentos sociais.

\section{Conclusões}

governo federal para lidar com os diferentes espaços de diálogo com a sociedade civil. Exemplo disso foi a criação da Secretaria Nacional de Articulação Social (SNAS), no interior da Secretaria-Geral da Presidência, a fim de coordenar e articular as relações políticas do governo com os diferentes segmentos da sociedade civil ${ }^{12}$. Entretanto, o esforço empreendido revelou uma ausência de articulação entre os diferentes mecanismos de participação.

A desarticulação institucional para viabilizar que as diferentes experiências de participação obtivessem condições de acesso ao órgão responsável pela integração intergovernamental, notadamente, a Casa Civil, revela a fragilidade do processo. Se o que se espera da participação é a qualificação da gestão pública e a real incidência da sociedade nos processos de elaboração das políticas, seria necessária uma maior articulação entre os espaços de participação e os locais de coordenação das ações de governo (Teixeira, Souza \& Lima 2012). Moroni (2006), ao observar essa estrutura institucional, afirma que a participação era concebida como estratégia de governabilidade, mas os sujeitos políticos da participação eram reconhecidos com pesos diferentes. Tal fato pode ser percebido pela própria vinculação inicial do CDES à SRI, e, após, à SAE, quando, pela lógica, deveria estar sob coordenação da Secretaria-Geral da Presidência e da SNAS, juntamente com os demais conselhos e conferências nacionais. Diferentemente de outras experiências mais consolidadas de diálogo com a sociedade civil, como, por exemplo, os conselhos nacionais nas áreas de saúde e assistência social, o CDES ainda busca sua legitimidade dentro da estrutura de participação do governo federal.

Este artigo buscou analisar a experiência do CDES no contexto de diversificação das oportunidades institucionais de diálogo com a sociedade civil no governo federal. A partir de 2003, foi gestada na administração pública federal a tentativa de construção de um pacto com a sociedade civil organizada, a partir do reconhecimento de que a sociedade e suas organizações podem qualificar a gestão e incidir nos processos decisórios, garantindo também a ampliação das bases de negociação e de sustentação política do governo. Destacamos que, no período, houve um aumento considerável no número de conselhos nacionais, contemplando temas diversos.

Dentre os conselhos consultivos, discorremos sobre a experiência do Conselho de Desenvolvimento Econômico e Social. Enquanto um novo formato de instituição participativa, o CDES propõe uma metodologia de debate ampliado para a busca de convergências, sem a votação das propostas que seguem para apreciação da Presidência. A tentativa de construção de documentos de forma consensual foi o diferencial de seu funcionamento, sendo que a concertação visou promover o diálogo e a negociação pela via do debate público, evitando o favorecimento de demandas setorializadas e a imposição de opiniões majoritárias. Apesar de possuir um elevado número de representantes da sociedade civil, o Conselho não se caracteriza como uma instância de participação popular, propriamente dita, em virtude de sua composição e funcionamento.

A pesquisa empreendida confirma estudos anteriores sobre a relevância do desenho institucional para a efetividade da participação (Fung 2004; Faria 2007; Avritzer 2008; Faria \& Ribeiro 2010; Avritzer 2011). Com base nos dados empíricos apresentados, concluímos que definição de critérios para composição, previsão de grupos de trabalho, diversificação dos participantes, possibilidade de alternância da presidência e regras para formulação da pauta são importantes indicadores das capacidades inclusiva e democrática no interior das instituições participativas. 
No caso do CDES, verificamos um alto nível de organização interna em função da estrutura de funcionamento, frequência das reuniões, coordenação de uma Secretaria-Executiva, atuação de comitê gestor e criação de grupos temáticos. No entanto, a análise do desenho institucional revelou problemas quanto ao potencial inclusivo em virtude da indefinição de critérios para a escolha dos participantes, sobrerrepresentação de determinados segmentos e impossibilidade de alternância da presidência.

Além do desenho institucional, fatores contextuais como a articulação interna de governo e a vontade política também impactaram sua efetividade, tendo em vista a necessidade de promover a sinergia entre os órgãos da administração pública que atuam na gestão de políticas com algum elemento participativo. Nesse sentido, a análise de fatores exógenos se revelou fundamental para a avaliação da efetividade da participação, tendo em vista que variáveis contextuais impactam a agenda, o encaminhamento das deliberações e a dinâmica de interação entre representantes da sociedade civil e atores estatais no interior das experiências participativas.

A fragilidade da coordenação governamental para a gestão dos processos participativos ocasionou baixo impacto do CDES na formulação das políticas, sobreposição da agenda governamental e, por consequência, limitações quanto à inclusão de pautas sugeridas pelos conselheiros da sociedade civil. O Conselho revela um alto nível de dependência do sistema político, uma vez que seu formato depende menos da organização da sociedade civil do que da vontade política e da correlação de forças no governo.

Mesmo que o governo Lula tenha iniciado a construção das bases para uma nova relação com a sociedade civil organizada, graças à institucionalização de novos espaços participativos, foi perceptível a dificuldade desse governo em articular a política participativa nos diversos órgãos da administração pública federal. Coube ao governo Dilma articular a estrutura governamental para incorporá-los na gestão das políticas públicas, mediante o próprio fortalecimento da coordenação da Secretaria-Geral da Presidência. Em 2014, o governo lançou a Política Nacional de Participação Social (PNPS) com o objetivo de fortalecer e articular os processos participativos na administração pública federal (Brasil 2014). Em virtude da reação de setores conservadores no Parlamento, a PNPS está sob ameaça, acirrando a tesão entre a proposta participativa e os mecanismos tradicionais de representação política.

As intensas manifestações que ocorreram nos meses de junho e julho de 2013 contribuíram para a reflexão sobre os limites do sistema político brasileiro, mas também sobre a fragilidade dos canais de participação existentes. Nesse sentido, é preciso qualificar os espaços já constituídos, possibilitando o efetivo compartilhamento dos processos decisórios. Para democratizar a gestão pública, os processos participativos necessitam contemplar atores sociais diversos, potencializando sua capacidade de incidir nas políticas públicas não somente em termos de agendamento, mas também nas etapas de formulação, implementação e monitoramento das ações governamentais.

Priscilla Ribeiro dos Santos (pciasantos@gmail.com) é Doutoranda em Ciência Política pela Universidade Federal do Rio Grande do Sul (UFRGS). Vínculo Institucional: Programa de Pós-Graduação em Ciência Política, UFRGS, Porto Alegre, RS, Brasil.

Alfredo Alejandro Gugliano (alfredogugliano@hotmail.com) é Doutor em Ciências Políticas e Sociologia pela Universidade Complutense de Madri, professor adjunto do Departamento de Ciência Política da Universidade Federal do Rio Grande do Sul (UFRGS) e pesquisador do CNPq. Vínculo institucional: Departamento de Ciência Política, UFRGS, Porto Alegre, RS, Brasil. 


\section{Referências}

Abers, R.; Serafim, L. \& Tatagiba, L., 2014. Repertórios de interação Estado-sociedade em um Estado heterogêneo: a experiência na Era Lula. Dados, 57(2), pp.325-357. DOI: 10.1590/0011-5258201411

Almeida, D. \& Cunha, E.S.M., 2011. A análise da deliberação democrática: princípios, conceitos e variáveis relevantes. In R.R.C. Pires, ed. Efetividade das instituições participativas no Brasil: estratégias de avaliação. Brasília: IPEA.

Avilés, A.O., 1992. Los Consejos Económicos e Sociales. Madrid: Trotta.

Avritzer, L., 2007. Sociedade Civil, instituições participativas e representação: da autorização à legitimidade da ação. Dados, 5(3), pp.443-464. DOI: 10.1590/S0011-52582007000300001

, 2008. Instituições participativas e desenho institucional: algumas considerações sobre a variação da participação no Brasil democrático. Opinião Pública,14(1),pp.43-64. DOI: 10.1590/S0104-62762008000100002 2010a. A dinâmica da participação local no Brasil. São Paulo: Cortez. 2010b. O papel da participação nas políticas sociais do governo federal. In F.S. Silva; F.G. Lopez \& R.R.C. Pires, eds. Estado, Instituições e Democracia. Brasília: IPEA.

Avritzer, L., 2011. A qualidade da democracia e a questão da efetividade da participação: mapeando o debate. In R.R.C. Pires, ed. Efetividade das instituições participativas no Brasil: estratégias de avaliação. Brasília: IPEA.

Avritzer, L. \& Navarro, Z., 2003. A inovação democrática no Brasil: o orçamento participativo. São Paulo: Cortez.

Avritzer, L. \& Pereira, M.L., 2005. Democracia, participação e instituições híbridas. Teoria e Sociedade, número especial, pp.16-41.

Bohman, J., 2009. O que é a deliberação pública? Uma abordagem dialógica. In A.C.S. Marques, ed. A deliberação pública e suas dimensões sociais políticas e comunicativas: textos fundamentais. Belo Horizonte: Autêntica.

Castiglione, D. \& Warren, M.E., 2006. Rethinking Democratic Representation: Eight theoretical issues. In Workshop Rethinking Democratic Representation. Columbia.

Cohen, J., 2009. Deliberação e legitimidade democrática. In A.C.S. Marques, ed. A deliberação pública e suas dimensões sociais políticas e comunicativas: textos fundamentais. Belo Horizonte: Autêntica.

Côrtes, S.M.V., 2002. Construindo a possibilidade da participação dos usuários: conselhos e conferências no Sistema Único de Saúde. Sociologias, 7, pp.18-49. DOI: 10.1590/S1517-45222002000100002

Costa, V.M.R., 2006. O CDES: a aprendizagem da pactuação. Disponível em: http://www.cdes.gov.br/documento/934178/o-cdes-a-aprendizagem-da-pactuacao.html. Acesso em: 9 nov. 2015.

Cunha, E.S.M., 2010. Inclusão social e política: o desafio deliberativo dos conselhos municipais de assistência social. In L. Avritzer, ed. A dinâmica da participação local no Brasil. São Paulo: Cortez.

Cunha, E.S.M.; Almeida, D.C.R.; Faria, C.F. \& Ribeiro, U.C. 2011. Uma estratégia multidimensional de avaliação dos conselhos de políticas: dinâmica deliberativa, desenho institucional e fatores exógenos. In R.R.C. Pires, ed. Efetividade das instituições participativas no Brasil: estratégias de avaliação. Brasília: IPEA.

Danéris, M.T., 2012. A gênese do Conselho de Desenvolvimento Econômico e Social do Rio Grande do Sul e a esfera pública institucionalizada. Dissertação (Mestrado em Ciência Política). Porto Alegre: Universidade Federal do Rio Grande do Sul.

Faria, C.F., 2000. Democracia deliberativa: Habermas, Cohen e Bohman. Lua Nova, 49, pp.47-68. DOI: 10.1590/S0102-64452000000200004

,2005. O Estado em movimento: complexidade social e participação política no Rio Grande do Sul. Tese (Doutorado em Ciência Política). Belo Horizonte: Universidade Federal de Minas Gerais.

,2007. Sobre os determinantes das políticas participativas: a estrutura normativa e o desenho institucional dos conselhos municipais da saúde e de direitos da criança e do adolescente no Nordeste. In L. Avritzer, ed. A participação social no Nordeste. Belo Horizonte: Ed. UFMG.

,2010. Estado e organizações da sociedade civil no Brasil contemporâneo: construindo uma sinergia positiva? Revista de Sociologia e Política, 18(36), pp.187-204. DOI: 10.1590/S0104-44782010000200012

Faria, C.F. \& Ribeiro, U.C., 2010. Entre o legal e o real: o que dizem as variáveis institucionais sobre os conselhos municipais de políticas públicas? In L. Avritzer, ed. A dinâmica da participação local no Brasil. São Paulo: Cortez.

Fleury, S., 2003. Concertação e efetividade da ação política: o Conselho de Desenvolvimento Econômico e Social do governo Lula. In $8^{\circ}$ Congreso Internacional del CLAD sobre la Reforma del Estado y de la Administración Pública. Panamá.

Fuks, M., 2007. Contexto, regras e efetividade deliberativa: considerações a respeito dos conselhos de Curitiba. In L. Avritzer, ed.A participação social no Nordeste. Belo Horizonte: Ed. UFMG.

Fung, A., 2004. Receitas para as esferas públicas: oito desenhos institucionais e suas consequências. In V.S. Coelho \& M. Nobre, eds. Participação e deliberação: teoria democrática e experiências institucionais no Brasil contemporâneo. São Paulo: Editora 34.

Fung, A. \& Wright, E.O., 2003. Deepening Democracy: Institutional Innovations in Empowered Participatory Governance. London: Verso.

Gurza Lavalle, A.; Houtzager, P.P. \& Castello, G., 2006. Democracia, pluralização da representação e sociedade civil. Lua Nova, 67, pp.49-104. DOI: 10.1590/S0102-64452006000200004

Horochovski, R.R. \& Clemente, A.J., 2012. Democracia deliberativa e orçamento público: experiências de participação em Porto Alegre, Belo Horizonte, Recife e Curitiba.Revista de Sociologia e Política, 20(43), pp.127-157. DOI: 10.1590/S0104-44782012000300007 
Kowarick, L., 2006. O Conselho de Desenvolvimento Econômico e Social: um processo em construção. Disponível em: http://www.cdes.gov.br/documento/300654/o-conselho-de-desenvolvimento-economico-e-social-um-processo-em-construcao-.html. Acesso em: 9 nov. 2015.

Kunrath, R.J., 2005. CDES: O Conselho de Desenvolvimento Econômico e Social do Brasil. Dissertação (Mestrado em Ciência Política). Porto Alegre: Universidade Federal do Rio Grande do Sul.

2012. Os conselhos econômicos e sociais em perspectiva comparada: os casos da Espanha e do Brasil. Tese (Doutorado em Ciência Política). Porto Alegre: Universidade Federal do Rio Grande do Sul.

Lüchmann, L.H.L., 2002. Democracia deliberativa: sociedade civil, esfera pública e institucionalidade. Cadernos de Pesquisa, 33, pp.1-38.

, 2007. A representação no interior das experiências de participação. Lua Nova, 70, pp.139-170. DOI: 10.1590/S0102-64452007000100007

Moroni, J.A., 2006. O direito à participação no governo Lula. Digit.

Pinto, C.R.J., 2004. A sociedade civil institucionalizada. Política \& Sociedade, 5, pp.99-116.

Pinto, E.C. \& Cardoso Jr., J.C., 2010. A experiência do CDES como espaço de concertação nacional para o desenvolvimento. In J.C. Cardoso Jr.; J.C. Santos \& J. Alencar, eds. Diálogos para o desenvolvimento: a experiência do conselho de desenvolvimento econômico e social sob o governo Lula. Brasília: IPEA.

Pires, R.R.C., 2011. Efetividade das instituições participativas no Brasil: estratégias de avaliação. Brasília: IPEA.

Pogrebinschi, T. \& Santos, F., 2011. Participação como representação: o impacto das Conferências Nacionais de Políticas Públicas no Congresso Nacional. Dados, 54(3), pp.259-305. DOI: 10.1590/S0011-52582011000300002

Ribeiro, D.M.F., 2009. A construção institucional do CDES: uma dinâmica favorável ao desenvolvimento? Observador on-line, 4(4), pp.1-26.

Santos, P.R., 2014. O Conselho de Desenvolvimento Econômico e Social e a nova agenda desenvolvimentista no Brasil. Revista do Serviço Público, 65(2), pp.137-162.

Schmitter, P., 1979. Still the Century of Corporatism? In P. Schmitter \& G. Lehbruch, eds. Trends Towards Corporatist Intermediation. New York: Sage Publications.

Silva, M.K., 2003. A expansão do orçamento participativo na região metropolitana de Porto Alegre: condicionantes e resultados. In L. Avritzer \& Z. Navarro, eds.A inovação democrática no Brasil: o orçamento participativo. São Paulo: Cortez.

Teixeira, A.; Souza, C. \& Lima, P., 2012. Arquitetura da participação no Brasil: uma leitura das representações políticas em espaços participativos nacionais. Rio de Janeiro: IPEA.

Vaz, A.C.N., 2011. Participação política, efeitos e resultados em políticas públicas: notas crítico-analíticas. Opinião Pública, 17(1), pp.163-205. DOI: 10.1590/S0104-62762011000100006

Vaz, A.C.N. \& Pires, R.R.C., 2011. Comparações entre municípios: avaliação dos efeitos da participação por meio de pares contrafactuais. In R.R.C. Pires, ed. Efetividade das instituições participativas no Brasil: estratégias de avaliação. Brasília: IPEA.

Wampler, B., 2003. Orçamento participativo: uma explicação para as amplas variações nos resultados. In L. Avritzer \& Z. Navarro, eds. A inovação democrática no Brasil: o orçamento participativo. São Paulo: Cortez.

, 2010. Transformando o Estado e a sociedade civil por meio da expansão das comunidades - política, associativa e de políticas públicas. In L. Avritzer, ed. A dinâmica da participação local no Brasil. São Paulo: Cortez.

\section{Outras fontes}

Brasil, 2003. Decreto n. 4 744, de 16 de junho de 2003. Dispõe sobre a composição e o funcionamento do Conselho de Desenvolvimento Econômico e Social. Diário Oficial da União, Brasília.

, 2013. Decreto n. 8.151, de 11 de dezembro de 2013. Transfere a Secretaria do Conselho de Desenvolvimento Econômico e Social da Secretaria de Assuntos Estratégicos da Presidência da República para a Casa Civil da Presidência da República e altera a Estrutura Regimental e o Quadro Demonstrativo dos Cargos em Comissão e das Funções Gratificadas da Secretaria de Assuntos Estratégicos da Presidência da República e da Casa Civil da Presidência da República. Diário Oficial da União, Brasília.

,2014. Decreto n. 8.243, de 23 de maio de 2014. Institui a Política Nacional de Participação Social - PNPS e o Sistema Nacional de Participação Social - SNPS, e dá outras providências. Diário Oficial da União, Brasília.

CDES. 2008. A Governança do CDES e a contribuição do CDES para a Governança do processo de desenvolvimento do Brasil: Termo de Referência. Disponível em: http://www.cdes.gov.br/grupo/241/comite-gestor-do-cdes.html Acesso em: 9 nov. 2015.

2009. Funcionamento do Conselho. Disponível http://www.cdes.gov.br/conteudo/8508/funcionamento-do-conselho.html. Acesso em: 9 nov. 2015. ,2012a. Atas das reuniões plenárias. Disponíveis em: http://www.cdes.gov.br/grupo/181/pleno-do-cdes.html. Acesso em: 9 nov. 20015.

,2012b. Galeria dos conselheiros. Disponível em: http://www.cdes.gov.br/galeria_conselho. Acesso em: 9 nov. 2015. ,2013. Matérias aprovadas. Disponível em: http://www.cdes.gov.br/materias_aprovadas.html. Acesso em: 9 nov. 2015. , 2014. Diálogo para o desenvolvimento: a criação de Conselhos de Desenvolvimento Econômico e Social. Disponível em: http://www.cdes.gov.br/conselhos-brasil.html. Acesso em: 9 nov. 2015. 
IPEA, 2010. Brasil em desenvolvimento: Estado, planejamento e políticas públicas. Brasília: IPEA. ,2012. Participação social como método de governo: um mapeamento das “interfaces socioestatais” nos programas federais. Comunicado n. 132. Brasília: IPEA.

SG/PR., 2013. Conselhos e Conferências. Disponível em: http://www.secretariageral.gov.br/art_social/conselhose-conferencias. Acesso em: 9 nov. 2013.

\begin{abstract}
In the last decade, Brazilian government has diversified the forums for dialogue with civil society in the management of public policies. The Council for Economic and Social Development (CDES) was created in 2003 to advise the Presidency about development policies. This article aims to analyze its effectiveness in terms of the dialogue with civil society in decision-making and its influence on government policies from 2003 to 2012. We investigate how the institutional design (endogenous factor) and the governmental coordination (exogenous or contextual factor) impacted on its effectiveness. This research adopted a qualitative methodology based on documentary analysis of the legislation, term of reference, minutes and other strategic documents produced by CDES. We conclude that the Councils effectiveness is impacted by problems related to democratization of internal processes, such as: lack of transparent criteria for the selection of their members and low capacity of inclusiveness of non-governmental counselors. The proximity to the political coordination and the lack of and the lack of interaction with other national participatory institutions affected the purposeful capacity and the effectiveness of deliberations. Considering that local and state administrations have created similar development councils, this study aims to contribute to the debate about the influence of institutional design and the governmental coordination on the qualification of participatory policies.
\end{abstract}

KEYWORDS: participation, civil society, Council for Economic and Social Development, public policies, effectiveness.

License information: This is an open-access article distributed under the terms of the Creative Commons Attribution License (CC-BY-NC 4.0), which permits unrestricted use, distribution, and reproduction in any medium, provided the original work is properly cited. 


\section{ERRATA}

No artigo Efetividade das políticas participativas no governo brasileiro: o Conselho de Desenvolvimento Econômico e Social, DOI 10.1590/1678-987315235601, publicado na Revista de Sociologia e Política Vol. 23 N. 56, p. 3-19, constatou-se o seguinte erro:

\section{Página 16}

\section{No quarto parágrafo, linha 11, onde se lê}

acirrando a tesão entre a proposta

\section{Leia-se}

acirrando a tensão entre a proposta 